\title{
Differential protein expression in chicken macrophages and heterophils in vivo following infection with Salmonella Enteritidis
}

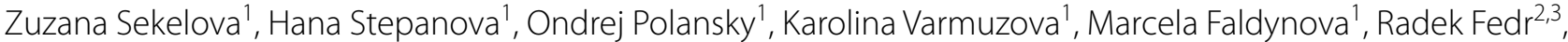 \\ Ivan Rychlik ${ }^{1 *}$ and Lenka Vlasatikova ${ }^{1}$
}

\begin{abstract}
In this study we compared the proteomes of macrophages and heterophils isolated from the spleen 4 days after intravenous infection of chickens with Salmonella Enteritidis. Heterophils were characterized by expression of MMP9, MRP126, LECT2, CATHL1, CATHL2, CATHL3, LYG2, LYZ and RSFR. Macrophages specifically expressed receptor proteins, e.g. MRC1L, LRP1, LGALS1, LRPAP1 and a DMBT1L. Following infection, heterophils decreased ALB and FN1, and released MMP9 to enable their translocation to the site of infection. In addition, the endoplasmic reticulum proteins increased in heterophils which resulted in the release of granular proteins. Since transcription of genes encoding granular proteins did not decrease, these genes remained continuously transcribed and translated even after initial degranulation. Macrophages increased amounts of fatty acid elongation pathway proteins, lysosomal and phagosomal proteins. Macrophages were less responsive to acute infection than heterophils and an increase in proteins like CATHL1, CATHL2, RSFR, LECT2 and GAL1 in the absence of any change in their expression at RNA level could even be explained by capturing these proteins from the external environment into which these could have been released by heterophils.
\end{abstract}

\section{Introduction}

Macrophages and heterophils represent professional phagocytes acting as effectors and modulators of innate immunity as well as orchestrators of adaptive immunity [1]. Heterophils, the avian counterparts of mammalian neutrophils, belong among the first responders to bacterial infections and sensing of pathogen associated molecular patterns (PAMPs) stimulates heterophils for phagocytosis as well as release of bactericidal proteins stored in heterophil granules into the extracellular environment [2]. In agreement with their general function in host protection against pathogens, heterophils play a crucial role in the protection of chickens against Salmonella infection and chickens with heterophil depletion are not protected against colonization of systemic sites [3-5]. However, although there are several reports on

\footnotetext{
*Correspondence: rychlik@vri.cz

${ }^{1}$ Veterinary Research Institute, Hudcova 70, 62100 Brno, Czech Republic Full list of author information is available at the end of the article
}

specific heterophil functions during infection of chickens with Salmonella enterica, their genome-wide response to infection has not been characterized so far.

Macrophages are professional phagocytes responsible for the destruction and clearance of pathogens. When activated, macrophages increase their antibacterial activity by the expression of antimicrobial peptides like cathepsins B, C, D and S, avidin, ferritin or ovotransferrin [6], and production of $\mathrm{NO}$ radicals from arginine by inducible NO synthase. The antimicrobial proteins expressed by macrophages are commonly produced also by heterophils though it is not known to what extent these may differ in their immediate availability and total amount produced by both cell types. Macrophages can also regulate the immune response by the expression of cytokines e.g. IL1 $\beta$, IL6, IL8, IL18 or LITAF [7] and are capable of antigen presentation [8-10]. However, similar to heterophils, an unbiased report on total proteome expressed by chicken macrophages is absent. 
In our previous study we showed that heterophils and macrophages increase in the spleen of chickens when intravenously infected with Salmonella Enteritidis ( $S$. Enteritidis) [7]. Next we characterized the gene expression at the tissue level in the whole spleen and expression of selected transcripts was tested in sorted leukocyte subpopulations [6]. However, none of this provided general data on the protein expression in chicken heterophils and macrophages. Although intravenous infection of chickens only partially represents specific Salmonella-chicken interactions which are mixed up with a general response to bacteremia caused by Gram negative bacterium, this way of infection represents a model for the understanding heterophil and macrophage functions during early response to infection. In the current study we therefore isolated heterophils and macrophages from chicken spleens by fluorescence-activated cell sorting (FACS), purified proteins from these cells and identified them by mass spectrometry. This allowed us to (1) characterize the total proteome of heterophils and macrophages, (2) define proteins which exhibited differential abundance in chicken heterophils compared to macrophages and (3) identify proteins that changed in abundance following the intravenous infection with $S$. Enteritidis in either of these populations. Since we also included a group of chickens which was vaccinated prior to challenge, we also addressed whether there are any proteins specifically expressed by the macrophages or heterophils from the vaccinated chickens. Using this approach we identified over one hundred proteins characteristic of either chicken heterophils or macrophages which allowed us to further refine their function in chickens.

\section{Materials and methods}

\section{Ethics statement}

The handling of animals in this study was performed in accordance with current Czech legislation (Animal protection and welfare Act No. 246/1992 Coll. of the Government of the Czech Republic). The specific experiments were approved by the Ethics Committee of the Veterinary Research Institute (permit number 5/2013) followed by the Committee for Animal Welfare of the Ministry of Agriculture of the Czech Republic (permit number MZe 1480).

\section{Bacterial strains and chicken line}

Newly hatched ISA Brown chickens from an egg laying line (Hendrix Genetics, Netherlands) were used in this study. Chickens were reared in perforated plastic boxes with free access to water and feed and each experimental or control group was kept in a separate room. The chickens were vaccinated with $S$. Enteritidis mutant completely lacking Salmonella pathogenicity island 1 (SPI-1) constructed as described earlier [11] and infected with isogenic wild type $S$. Enteritidis 147 spontaneously resistant to nalidixic acid. The strains were grown in LB broth at $37^{\circ} \mathrm{C}$ for $18 \mathrm{~h}$ followed by pelleting bacteria at $10000 \times g$ for $1 \mathrm{~min}$ and re-suspending the pellet in the same volume of PBS as was the original volume of LB broth.

\section{Experimental infection}

There were 3 groups of chickens. Six chickens from the control group were sacrificed on day 48 of life. An additional 6 chickens (group 2) were infected intravenously with $10^{7}$ CFU of wild type $S$. Enteritidis in $0.1 \mathrm{~mL}$ PBS on day 44 of life. The last 6 chickens (group 3) were orally vaccinated on day 1 , revaccinated on day 21 of life with $10^{7} \mathrm{CFU}$ of $S$. Enteritidis SPI- 1 mutant in $0.1 \mathrm{~mL}$ of inoculum and challenged intravenously with $10^{7} \mathrm{CFU}$ of wild type $S$. Enteritidis on day 44 of life. Intravenous mode of infection was used mainly to stimulate macrophage and heterophil response rather than to model natural infection of chickens with $S$. Enteritidis. All chickens in groups 2 and 3 were sacrificed 4 days post infection, i.e. when aged 48 days. The spleens from the chickens from all three groups were collected into PBS during necropsy. To confirm $S$. Enteritidis infection, approximately $0.5 \mathrm{~g}$ of liver tissue was homogenised in $5 \mathrm{~mL}$ of peptone water, tenfold serially diluted and plated in XLD agar, as described previously [11].

\section{Collecting heterophil and macrophage subpopulations by flow cytometry}

The cell suspensions were prepared by pressing the spleen tissue through a fine nylon mesh followed by 2 washes with $30 \mathrm{~mL}$ of cold PBS. After the last washing step, the splenic leukocytes were re-suspended in $1 \mathrm{~mL}$ of PBS and used for surface marker staining.

In total $10^{8}$ of cells were incubated for $20 \mathrm{~min}$ with antimonocyte/macrophage:FITC (clone KUL01 from Southern Biotech) and CD45:APC (clone LT40 from Southern Biotech), followed by wash with PBS. Monocytes/macrophages (CD45+KUL01+) and heterophils (identified based on FSC/SSC characteristics within CD45+ cells) were sorted using a FACSFusion flow cytometer operated by FACSDiva software (BD Biosciences). Only for simplicity, the monocytes/macrophages population will be called as "macrophage (Ma)" in the rest of this paper. Sorted cells were collected in PBS and immediately processed as described below. A small aliquot from each sample was subjected to immediate purity analysis. The purity of macrophages was $88.6 \pm 5.3 \%$ and of heterophils $88.1 \pm 4.2 \%$ when counting cell of expected staining, and FSC and SSC parameters out of all particles. When we gated at the area with live cells, the purity of macrophages and heterophils was between 97 and $98 \%$. 
Majority of contaminants therefore represented cellular debris and only around $2.5 \%$ of contaminants were formed by non-target cells.

\section{Protein and RNA isolation from sorted cells, reverse transcription of $\mathrm{mRNA}$ and quantitative real time PCR (qPCR)}

Sorted leukocyte subpopulations were lysed in $500 \mu \mathrm{L}$ of Tri Reagent (MRC) for parallel isolation of RNA and proteins. Upon addition of 4-bromoanisole and $15 \mathrm{~min}$ centrifugation at $14000 \times g$, proteins were precipitated with acetone from the lower organic phase. RNA present in upper aqueous phase was further purified using RNeasy purification columns according to the instructions of the manufacturer (Qiagen). The concentration of RNA was determined spectrophotometrically (Nanodrop, Thermo Scientific) and $1 \mu \mathrm{g}$ of RNA was immediately reverse transcribed into cDNA using MuMLV reverse transcriptase (Invitrogen) and oligo dT primers. After reverse transcription, the cDNA was diluted 10 times with sterile water and stored at $-20{ }^{\circ} \mathrm{C}$ prior qPCR. qPCR was performed in $3 \mu \mathrm{L}$ volumes in 384-well microplates using QuantiTect SYBR Green PCR Master Mix (Qiagen) and a Nanodrop pipetting station from Innovadyne for PCR mix dispensing following MIQE recommendations [12]. Amplification of PCR products and signal detection were performed using a LightCycler II (Roche) with an initial denaturation at $95{ }^{\circ} \mathrm{C}$ for $15 \mathrm{~min}$ followed by 40 cycles of $95{ }^{\circ} \mathrm{C}$ for $20 \mathrm{~s}, 60{ }^{\circ} \mathrm{C}$ for $30 \mathrm{~s}$ and $72{ }^{\circ} \mathrm{C}$ for $30 \mathrm{~s}$, followed by the determination of melting temperature of resulting PCR products to exclude false positive amplification. Each sample was subjected to qPCR in duplicate and the mean values of the $\mathrm{Cq}$ values of genes of interest were normalized $(\Delta \mathrm{Ct})$ to an average $\mathrm{Cq}$ value of three reference genes (GAPDH, TBP and UB). The relative expression of each gene of interest was finally calculated as $2^{-\Delta \mathrm{Cq}}$. Statistical analysis using a two sample $t$ test for means equality was performed when comparing levels of mRNA expression between chicken groups and results with $p$ value $\leq 0.05$ were considered as significantly different in expression. Sequence of reference genes GAPDH, TBP and UB have been published elsewhere $[13,14]$. Sequences of all newly designed primers used in this study including their location within different exons and sizes of PCR products are listed in Additional file 1.

\section{Sample preparation for LC-MS/MS analysis}

Precipitated proteins were washed with acetone and dried. The pellets were dissolved in $300 \mu \mathrm{L}$ of $8 \mathrm{M}$ urea and processed by the filter aided sample preparation method [15] using Vivacon $10 \mathrm{kDa}$ MWCO filter (Sartorius Stedim Biotech). Proteins were washed twice with $100 \mu \mathrm{L}$ of $8 \mathrm{M}$ urea and reduced by $100 \mu \mathrm{L}$ of $10 \mathrm{mM}$
DTT. After reduction, proteins were incubated with $100 \mu \mathrm{L}$ of $50 \mathrm{mM}$ IAA and washed twice with $100 \mu \mathrm{L}$ of $25 \mathrm{mM}$ TEAB. Trypsin (Promega) was used at 1:50 ratio $(\mathrm{w} / \mathrm{w})$ and the digestion proceeded for $16 \mathrm{~h}$ at $30^{\circ} \mathrm{C}$.

For comparative analysis, peptide concentration was determined spectrophotometrically (Nanodrop, Thermo Scientific) and samples from the same group of chickens were pooled. Pooled samples were then labelled using the stable isotope dimethyl labelling protocol as described previously [16]. Labeled samples were mixed and 3 subfractions were prepared using Oasis MCX Extraction Cartridges (Waters). The samples were desalted on SPE C18 Extraction Cartridges (Empore) and concentrated in a SpeedVac (Thermo Scientific) prior to LC-MS/MS.

\section{LC-MS/MS analysis}

Protein samples were analysed on LC-MS/MS system using an UltiMate 3000 RSLCnano liquid chromatograph (Dionex) connected to LTQ-Orbitrap Velos Pro mass spectrometer (Thermo Scientific). Chromatographic separation was performed on EASY-Spray C18 separation column $(25 \mathrm{~cm} \times 75 \mu \mathrm{m}, 3 \mu \mathrm{m}$ particles, Thermo Scientific) with $2 \mathrm{~h}$ long (label free) or $3 \mathrm{~h}$ long (label based) 3-36\% acetonitrile gradient.

High resolution (30 000 FWHM at $400 \mathrm{~m} / z$ ) MS spectra were acquired for the $390-1700 \mathrm{~m} / \mathrm{z}$ interval in an Orbitrap analyser with an AGC target value of $1 \times 10^{6}$ ions and maximal injection time of $100 \mathrm{~ms}$. Low resolution MS/MS spectra were acquired in Linear Ion Trap in a data-dependent manner and the top 10 precursors exceeding a threshold of 10000 counts and having a charge state of +2 or +3 were isolated within a $2 \mathrm{Da}$ window and fragmented using CID.

\section{Data processing, protein identification and quantification}

Raw data were analysed using the Proteome Discoverer (v.1.4). MS/MS spectra identification was performed by SEQUEST using the Gallus gallus protein sequences obtained from Uniprot database. Precursor and fragment mass tolerance were $10 \mathrm{ppm}$ and $0.6 \mathrm{Da}$, respectively. Carbamidomethylation $(\mathrm{C})$ and oxidation $(\mathrm{M})$ were set as static and dynamic modifications, respectively. Dimethylation $(\mathrm{N}$-term and $\mathrm{K})$ was set as static modification in the label-based analysis. Only peptides with a false discovery rate FDR $\leq 5 \%$ were used for protein identification.

Spectral counting, the protocol in which abundance of a protein is expressed as the total number of tandem mass spectra matching its peptides (peptide spectrum matches, PSM), was used for comparative label-free analysis of heterophil and macrophage proteomes [17]. For a general comparison of protein abundance between heterophils and macrophages, PSMs belonging to a particular protein from all three groups of chickens, i.e. 18 
samples, were summed up. The identification of at least two distinct peptides belonging to the particular protein and the threshold of at least 5 PSMs in at least one sample was required for its reliable identification [18, 19]. All data were normalized to the total number of PSMs in individual samples. Statistical analysis using a $t$ test was performed and the proteins with $p$ value $\leq 0.05$ and with at least four fold differences in its amounts were considered as significantly different in their abundance between the subpopulations.

In the label-based quantification, only unique peptide sequences with at least 20 PSMs were considered for peptide ratio calculations. Subsequent analysis of labelbased data was performed in R (https://www.R-project. org). For each protein, its individual peptide ratios were $\log _{2}$ transformed, mean values were calculated and tested with a one sample $t$ test. Benjamini-Hochberg correction for multiple testing was then applied to the obtained $p$ values. Only proteins having $\geq$ twofold change and adjusted $p$ value $\leq 0.05$ were considered as being significantly different in abundance.

\section{Bioinformatic analysis}

Protein interaction networks were built using the online database resource Search Tool for the Retrieval of Interacting Genes (STRING). Proteins were further analyzed using Gene Ontology (GO) database and the Kyoto Encyclopedia of Genes and Genomes (KEGG) for their classification into specific pathways. PCA plots were calculated and created in R (https://www.R-project.org).

\section{Results}

\section{S. Enteritidis infection}

Intravenous $S$. Enteritidis infection resulted in a high colonization of systemic sites. Average $\log _{10} S$. Enteritidis counts were $5.03 \pm 0.54$ and $3.06 \pm 0.99 \mathrm{CFU} / \mathrm{g}$ of liver in the infected chickens and the vaccinated and infected chickens, respectively. Despite this, no fatalities were observed among infected chickens. No $S$. Enteritidis was detected in any of the control non-infected chickens.

\section{Identification of heterophil and macrophage specific proteins}

Proteins specific for chicken heterophils or macrophages were determined irrespective whether these were obtained from the infected or non-infected chickens.

Altogether, 858 proteins from heterophils and 1032 proteins from macrophages were detected. Out of these, 654 proteins were expressed both in heterophils and macrophages. Two-hundred and eight proteins were detected in macrophages only and an additional 126 proteins were 4 times or more abundant in macrophages than in heterophils. On the other hand, 34 proteins were detected in heterophils only and an additional 44 proteins were 4 times or more abundant in heterophils than in macrophages (Additional file 2).

\section{Proteins characteristic for heterophils}

Out of 78 proteins characteristic for heterophils (Additional file 2), 20 with the highest PSM difference between heterophils and macrophages are listed in Table 1. These included MRP126, LECT2, CATHL1, CATHL2, CATHL3, LYG2, LYZ and RSFR proteins, all with antibacterial functions. STOM and RAB27A proteins controlling storage and release of granular proteins in neutrophils also belonged among the characteristic and highly expressed proteins in heterophils. Two serine protease inhibitors, SERPINB10 and SERPINB1, were also found among the 20 most characteristic heterophil proteins (Table 1). Only a single KEGG pathway was specifically enriched in heterophils and this was the starch and sucrose metabolism pathway comprising PYGL, PGM1 and PGM2 proteins $(p=1.7 \mathrm{E}-4)$. Despite the KEGG pathway designation, all these proteins represent enzymes involved in glycogen metabolism [20].

\section{Proteins characteristic for macrophages}

Out of 334 proteins specific for macrophages (Additional file 2), 20 with the highest PSM difference between macrophages and heterophils are listed in Table 2. Five of these represented receptor proteins MRC1L, LRP1, LGALS1, LRPAP1 and DMBT1L, the last one containing the scavenger receptor cysteine-rich (SRCR) domain. CTSB, CKB, MECR, PHB2, H9KZK0 and p41/Li are involved in phagocytosis and antigen presentation. An additional 4 proteins UQCR, UQCRC1, ACO2 and HADHB are localized to the mitochondria. Only 3 proteins, MRC1L, HSP70 and $\mathrm{p} 41 / \mathrm{Li}$, were already recorded in chicken macrophages [21-23] although except for NAT3, PLB and SSB, the expression of the remaining proteins (out of the most abundant listed in Table 2) has been already recorded in murine or human macrophages. Proteins enriched in macrophages belonged to oxidative phosphorylation $(p=4.7 \mathrm{E}-8)$, fatty acid metabolism $(p=1.73 \mathrm{E}-6)$, citrate cycle $(p=4.2 \mathrm{E}-6)$, arginine and proline metabolism $(p=8.5 \mathrm{E}-8)$ and proteasome $(p=4.5 \mathrm{E}-4)$.

\section{Heterophil proteins responding to in vivo infection with $S$. Enteritidis}

Altogether, 153 proteins were present in different abundance in the heterophils before and after $S$. Enteritidis infection. Of these, 109 proteins increased and 44 proteins decreased in abundance (Additional files 3 and 4 for all quantified heterophil proteins). Proteins belonging to 2 KEGG categories were enriched in heterophils 
Table 1 Twenty most characteristic proteins of heterophils (Het) compared to macrophages (Ma)

\begin{tabular}{|c|c|c|c|c|c|c|}
\hline Acc. no. & Protein name & Gene ID & $\Delta \mathrm{PSM}^{\mathrm{a}}$ & Fold ratio Het:Ma & Response to the infection & Function \\
\hline P28318 & MRP126, calprotectin & MRP126 & 7170 & 9.07 & No & Calcium and zinc binding \\
\hline P08940 & Myeloid protein 1 & LECT2 & 5532 & 6.32 & Decrease & Chemotactic factor for Het \\
\hline P02789 & Ovotransferrin & OTFB & 2351 & 4.87 & Decrease & Iron binding, immune response \\
\hline O73790 & $\begin{array}{l}\text { Heterochromatin-associated } \\
\text { protein MENT }\end{array}$ & SERPINB10 & 1760 & 6.00 & No & $\begin{array}{l}\text { DNA condensation, cysteine } \\
\text { protease inhibitor }\end{array}$ \\
\hline E1COK1 & $\begin{array}{l}\text { Extracellular fatty acid-binding } \\
\text { protein }\end{array}$ & ExFABP & 1742 & 4.94 & No & $\begin{array}{l}\text { Fatty acid and bacterial sidero- } \\
\text { phores binding }\end{array}$ \\
\hline F1NG13 & Transglutaminase 3 & TGM3 & 1572 & 19.94 & No & Transglutaminase \\
\hline Q2IAL7 & Cathelicidin 2 & CATHL2 & 1402 & 7.49 & Decrease & Antimicrobial peptide \\
\hline P27042 & Lysozyme G & LYG2 & 989 & 4.57 & Decrease & Antimicrobial peptide \\
\hline Q2IAL6 & Cathelicidin 3 & CATHL3 & 936 & 5.37 & No & Antimicrobial peptide \\
\hline P00698 & Lysozyme C & LYZ & 839 & 5.17 & Decrease & Antimicrobial peptide \\
\hline Q6QLQ5 & Cathelicidin 1 & CATHL1 & 833 & 4.62 & Decrease & Antimicrobial peptide \\
\hline E1BTH1 & Leukocyte elastase inhibitor & SERPINB1 & 627 & Only Het & Decrease & Protection against own proteases \\
\hline F1P284 & Leukotriene A(4) hydrolase & LTA4H & 603 & 5.78 & Decrease & $\begin{array}{l}\text { Epoxide hydrolase and amin- } \\
\text { opeptidase }\end{array}$ \\
\hline F1NGT3 & Matrix metallopeptidase 9 & MMP9 & 600 & Only Het & Decrease & $\begin{array}{l}\text { Degradation of the extracellular } \\
\text { matrix }\end{array}$ \\
\hline F2Z4L6 & Serum albumin & ALB & 557 & 4.79 & Decrease & Plasma carrier \\
\hline P30374 & Ribonuclease homolog & RSFR & 548 & 6.89 & Decrease & Lysosomal cysteine protease \\
\hline R9PXN7 & $\begin{array}{l}\text { Hematopoietic prostaglandin D } \\
\text { synthase }\end{array}$ & HPGDS & 504 & 17.79 & No & $\begin{array}{l}\text { Cytosolic glutathione S-trans- } \\
\text { ferases }\end{array}$ \\
\hline E1BTV1 & Stomatin & STOM & 502 & 23.82 & No & Integral membrane protein \\
\hline D2D3P4 & Rab27a & Rab27a & 435 & 88.08 & No & Small GTPase, exocytosis \\
\hline R4GI24 & Integrin alpha-D & ITGAD & 379 & 7.73 & No & Adhesion of leukocytes \\
\hline
\end{tabular}

${ }^{a}$ The difference in PSM counts of particular protein in Het and Ma.

following $S$. Enteritidis infection. These included the category translation with 39 proteins $(p=2.58 \mathrm{E}-62)$ and protein processing in endoplasmic reticulum (12 proteins, $p=1.74 \mathrm{E}-11$ ). Twenty proteins with the highest increase in abundance, except for those belonging to the category translation, are listed in Table 3. Among others, these included AVD, F13A, ANXA2, ANXA7 or CTSC.

Forty-four proteins decreased in abundance in heterophils following $S$. Enteritidis infection and 20 of these with the highest decrease are listed in Table 4. Proteins with decreased abundance were those found in heterophil granules such as MPO, LYZ, LYG2, CTSG, CTSL1, CATHL1, CATHL2, RSFR, MMP9 and LECT2. Another set of proteins which decreased in heterophils following $S$. Enteritidis infection included ALB, FN1 and OTFB (Table 4).

\section{Macrophage proteins responding to in vivo infection with S. Enteritidis}

Four KEGG pathways were specifically enriched when testing proteins of increased abundance in macrophages following $S$. Enteritidis infection. These included fatty acid elongation pathway (MECR and HADHB proteins, $p=2.49 \mathrm{E}-4)$, lysosomal proteins CTSB and CTSC $(p=6.98 \mathrm{E}-3)$, phagosomal proteins RAB7A and STX7 $(p=9.23 \mathrm{E}-3)$ and LDHA and HADHB from the microbial metabolism in diverse environments pathway $(p=9.4 \mathrm{E}-3)$. Other proteins with increased abundance in macrophages following $S$. Enteritidis infection were MRP126, CATHL1, CATHL2, GAL1, CTSB, CTSC, RSFR, SOD1, LECT2, LY86 and FTH, all with antibacterial functions (Table 5). Proteins which decreased in abundance in macrophages following $S$. Enteritidis infection included RBMX, NDUFA4, FNBP1, FAM107, STMN1, GLOD4 and OLA1 (Table 5; Additional files 5, 6 for all quantified macrophage proteins).

\section{RNA expression}

Finally we verified the expression of 37 genes coding for selected proteins listed in Tables 1, 2, 3, 4 and 5. Expression of 4 genes, LRP1, MPO, PPIB and TUBA3A was too low and these genes were excluded from further consideration (Additional file 7).

Six genes (LGALS1, MRC1L, GDA, MECR, DMBT1, LRPAP1) out of 7 proteins selected as specific for macrophages were transcribed in macrophages at a higher 
Table 2 Twenty most characteristic proteins for macrophages (Ma) compared to heterophils (Het)

\begin{tabular}{|c|c|c|c|c|c|c|}
\hline Acc. no. & Protein name & Gene ID & $\triangle \mathrm{PSM}^{\mathrm{a}}$ & Fold ratio Ma:Het & Response to the infection & Function \\
\hline M1XGZ4 & $\begin{array}{l}\text { Macrophage mannose receptor } \\
1 \text { like }\end{array}$ & MRC1L & 993 & Only Ma & No & C-Type lectin \\
\hline P98157 & $\begin{array}{l}\text { Low-density lipoprotein } \\
\text { receptor-related protein } 1\end{array}$ & LRP1 & 810 & Only Ma & No & Endocytic receptor \\
\hline P07583 & Galectin 1 & LGALS1 & 607 & Only Ma & No & Beta-galactoside-binding lectin \\
\hline P43233 & Cathepsin B & CTSB & 538 & 8.42 & Increase & Cysteine protease \\
\hline F1NZ86 & Heat shock 70 protein, mortalin & HSP70 & 508 & 5.30 & No & Chaperon \\
\hline P05122 & Creatine kinase B-type & CKB & 467 & 34.77 & No & Energy transduction \\
\hline F1NDD6 & $\begin{array}{l}\text { LDL receptor related protein } \\
\text { associated protein } 1\end{array}$ & LRPAP1 & 374 & Only Ma & No & LDL receptors trafficking \\
\hline F1NIX4 & Trans-2-enoyl-CoA reductase & MECR & 356 & 33.16 & Increase & Fatty acid elongation \\
\hline F1P180 & Aspartate aminotransferase & GOT2 & 350 & 7.27 & No & Transaminase \\
\hline P13914 & Arylamine $\mathrm{N}$-acetyltransferase & NAT3 & 350 & 23.92 & No & Conjugating enzyme \\
\hline H9KZKO & $\begin{array}{l}\text { Protein containing the scav- } \\
\text { enger receptor cysteine-rich } \\
\text { (SRCR) domain }\end{array}$ & DMBT1L & 318 & Only Ma & No & Scavenger receptor \\
\hline E1BZF7 & Putative phospholipase B & PLB & 317 & 6.23 & No & $\begin{array}{l}\text { Removing fatty acids from phos- } \\
\text { pholipids }\end{array}$ \\
\hline Q6J613 & Invariant chain isoform p41 & $\mathrm{Li}$ & 312 & 6.87 & No & Chaperone \\
\hline F1P582 & $\begin{array}{l}\text { Mitochondrial ubiquinol- } \\
\text { cytochrome-c reductase } \\
\text { complex core protein } 2\end{array}$ & UQCR & 309 & 4.36 & No & Oxidative phosphorylation \\
\hline Q5ZMW1 & $\begin{array}{l}\text { Aconitate hydratase, mitochon- } \\
\text { drial }\end{array}$ & ACO2 & 306 & 6.17 & No & TCA cycle \\
\hline F1NAC6 & $\begin{array}{l}\text { Cytochrome b-cl complex } \\
\text { subunit } 1\end{array}$ & UQCRC1 & 289 & 6.42 & No & Oxidative phosphorylation \\
\hline F6R1X6 & Lupus la protein & SSB & 288 & 6.90 & No & $\begin{array}{l}\text { Protecting of } 3^{\prime} \text { poly }(U) \text { terminus } \\
\text { of transcribed RNA }\end{array}$ \\
\hline E1BTT4 & $\begin{array}{l}\text { Trifunctional enzyme subunit } \\
\text { beta, mitochondrial }\end{array}$ & $\mathrm{HADHB}$ & 287 & 30.61 & Increase & $\beta$-Oxidation of fatty acids \\
\hline Q5ZMN3 & Prohibitin-2 & PHB2 & 282 & 10.52 & No & Not clear \\
\hline F1NJD6 & Guanine deaminase, cypin & GDA & 275 & Only Ma & No & $\begin{array}{l}\text { Oxidizes hypoxanthine to } \\
\text { xanthine }\end{array}$ \\
\hline
\end{tabular}

a The difference in PSM counts of particular protein in Ma and Het.

level than in heterophils. Only HSP70 was transcribed in macrophages and heterophils at the same level though it was present in higher abundance at the protein level in macrophages. Nine genes (MRP126, OTFB, LYG2, LYZ, SERPINB1, CATHL1, CATHL2, MMP9, LECT2) out of 14 heterophil specific proteins were transcribed in heterophils at a higher level than in macrophages. Two genes of this group (GPX, CTSG) were transcribed in heterophils and macrophages at the same level and the remaining 2 genes (RSFR, LTA4H) were transcribed at a higher level in macrophages though protein mass spectrometry indicated their higher abundance in heterophils.

Expression of 11 proteins which increased in abundance in macrophages following infection of chickens with $S$. Enteritidis was also tested at the RNA level. Except for MRP126, 10 of these (MECR, CTSC, ERAP1, RSFR, SOD1, CALR, CATHL1, CATHL2, LECT2, GAL1) did not exhibit any difference at the transcriptional level.
6 of 7 proteins (ANXA2, F13A, CTSC, ERAP1, AVD, HSP90B1) exhibiting an increased abundance in heterophils following infection of chickens with $S$. Enteritidis, also increased their expression at the level of transcription. Only IFITM did not change its expression at the RNA level. Finally we verified the expression of 11 proteins which decreased in abundance in heterophils following infection of chickens with $S$. Enteritidis. Eight of them (FN1, ALB, CTSL1, OTFB, LYZ, CATHL1, MMP9, LECT2) did not change their expression at the level of transcription and transcripts of 3 of them (RSFR, LYG2, CSTC) even increased following infection.

Similar to the results of protein mass spectrometry, RNA levels of the tested genes in the heterophils or macrophages from the vaccinated chickens were in between the expression in non-infected chickens and chickens infected without previous vaccination. Only 3 genes in heterophils did not follow this scheme and CATHL1, 
Table 3 Proteins which increased in abundance in heterophils in response to S. Enteritidis infection

\begin{tabular}{|c|c|c|c|c|c|}
\hline Acc. no. & Protein name & Gene ID & Fold ratio Inf: noninf & Fold ratio vac: noninf & Function \\
\hline P02701 & Avidin & AVD & $55.57^{*}$ & $32.06^{*}$ & Biotin binding \\
\hline F1P4F4 & Translocon-associated protein & SSR1 & $9.22^{*}$ & 6.36 & Protein translocase \\
\hline P17785 & Annexin A2 & ANXA2 & $6.44^{*}$ & 2.11 & $\begin{array}{l}\text { Activates macrophages for cytokine } \\
\text { production }\end{array}$ \\
\hline E1BWG1 & Coagulation factor XIIIA & F13A & $5.63^{*}$ & $2.60^{*}$ & $\begin{array}{l}\text { Crosslinking of fibrin chains, entrap- } \\
\text { ment of bacteria }\end{array}$ \\
\hline R4GJX3 & $\begin{array}{l}\text { Interferon-induced transmembrane } \\
\text { protein }\end{array}$ & IFITM & $4.99^{*}$ & 1.73 & $\begin{array}{l}\text { Acidification of the endosomal } \\
\text { compartments, mediator of the host } \\
\text { antiviral response }\end{array}$ \\
\hline F1NK96 & Protein disulfide-isomerase A6 & PDIA6 & $4.33^{*}$ & $2.66^{*}$ & Protein foldase \\
\hline F1NVA4 & Nucleophosmin & NPM1 & $3.68^{*}$ & 1.87 & Alarmin, nuclear chaperon \\
\hline F1NT28 & Inorganic pyrophosphatase & PPA1 & $3.52^{*}$ & 1.67 & $\begin{array}{l}\text { Hydrolysis of inorganic pyrophosphate } \\
\text { (PPi) }\end{array}$ \\
\hline Q90593 & 78 kDa glucose-regulated protein & $\mathrm{BiP}$ & $3.44^{*}$ & 1.94 & Chaperon \\
\hline F1NWB7 & Endoplasmin & HSP90B1 & $3.33^{*}$ & 1.99 & Chaperon \\
\hline E1C1D1 & Annexin 7 & ANXA7 & $3.27^{*}$ & $2.68^{*}$ & $\begin{array}{l}\text { Granular membranes fusion and } \\
\text { degranulation }\end{array}$ \\
\hline P24367 & Peptidyl-prolyl cis-trans isomerase B & PPIB & $3.26^{*}$ & $2.23^{*}$ & $\begin{array}{l}\text { Regulation of protein folding and } \\
\text { maturation }\end{array}$ \\
\hline E1C2S1 & Talin-1 & TLN1 & $3.12^{*}$ & $2.56^{*}$ & Activation of neutrophils \\
\hline Q49B65 & EF hand-containing protein 1 & EFHD1 & $3.12^{*}$ & 1.72 & Calcium binding \\
\hline F1NWG2 & Cathepsin C & CTSC & $3.10^{*}$ & 1.99 & $\begin{array}{l}\text { Activates serine proteases (elastase, } \\
\text { cathepsin } \mathrm{G} \text { and granzymes) }\end{array}$ \\
\hline F1NDY9 & Protein disulfide-isomerase A4 & PDIA4 & $2.93^{*}$ & 1.86 & Protein foldase \\
\hline E1C8M9 & Calnexin & CANX & $2.88^{*}$ & 1.75 & $\begin{array}{l}\text { Integral protein of the endoplasmic } \\
\text { reticulum }\end{array}$ \\
\hline E1BQN9 & Calcyclin-binding protein & CACYBP & $2.88^{*}$ & $2.38^{*}$ & Calcium-dependent ubiquitination \\
\hline H9L340 & ATP synthase subunit beta & ATP5B & $2.82^{*}$ & 1.56 & Energy metabolism \\
\hline F1NB92 & $\begin{array}{l}\text { Endoplasmic reticulum aminopepti- } \\
\text { dase } 1\end{array}$ & ERAP1 & $2.78^{*}$ & 0.89 & $\begin{array}{l}\text { Antigen processing and presentation of } \\
\text { endogenous peptide via MHC class I }\end{array}$ \\
\hline
\end{tabular}

* Significantly different from the expression in heterophils from the non-infected chickens.

CATHL2 and LECT2 were expressed in heterophils from the vaccinated chickens at significantly higher level than in the heterophils from infected chickens.

\section{Discussion}

Until now, chicken heterophils and macrophages have been characterized only by their specific characteristics like cytokine signaling or production of antimicrobial peptides $[2,6,7,24,25]$ and an unbiased report characterizing their total proteome, before and after infection, has been missing. In the current study we therefore isolated proteins from heterophils and macrophages and quantified their abundance before and after infection with $S$. Enteritidis by mass spectrometry. We have to remind that mass spectrometry provides reliable data for approximately 800 the most abundant proteins. The lowly represented proteins, despite their potential specificity or responsiveness to infection, could not be therefore detected.
Chicken macrophages differed from heterophils in 3 specific features. First, macrophages specifically expressed receptors such as MRC1L, LRP1, LGALS1, LRPAP1 and DMBT1L. Second, macrophages exhibited higher mitochondrial activity including fatty acid degradation, TCA cycle and oxidative phosphorylation. And third, macrophages specifically expressed enzymes involved in arginine and proline metabolism (Figure 1). Receptors specifically expressed by macrophages indicate their potential to sense signals from the external environment which allows them to modulate immune response $[6,7]$ including their own polarization $[26,27]$. The dependency of macrophages on oxidative phosphorylation and mitochondria functions was already described for human macrophages and neutrophils [28]. Macrophages were also enriched in arginine and proline metabolism since one of their bactericidal activities is the production of NO radicals by iNOS and arginine [29]. Following infection with $S$. Enteritidis, macrophages 
Table 4 List of proteins which decreased in abundance in heterophils in response to S. Enteritidis infection

\begin{tabular}{|c|c|c|c|c|c|}
\hline Acc. no. & Protein name & Gene ID & Fold ratio inf: noninf & Fold ratio vac: noninf & Function \\
\hline F1P1U6 & Myeloperoxidase & MPO & $0.013^{*}$ & $0.071^{*}$ & Oxidative burst \\
\hline E1C677 & Natural killer cell activator & Gga.18306 & $0.026^{*}$ & $0.21^{*}$ & $\begin{array}{l}\text { GO prediction: regulation of cytokine } \\
\text { biosynthetic process }\end{array}$ \\
\hline F1NJT3 & Fibronectin & FN1 & $0.11^{*}$ & 0.56 & $\begin{array}{l}\text { Binds components of extracellular } \\
\text { matrix }\end{array}$ \\
\hline F1NFQ7 & Serine protease 57 & PRSSL1 & $0.15^{*}$ & $0.37^{*}$ & Serine-type endopeptidase activity \\
\hline P00698 & Lysozyme C & LYZ & $0.16^{*}$ & $0.37^{*}$ & Antimicrobial peptide \\
\hline H9L027 & Cathepsin G & CTSG & $0.19^{*}$ & $0.30^{*}$ & Lysosomal cysteine protease \\
\hline Q6QLQ5 & Cathelicidin-1 & CATHL1 & $0.20^{*}$ & 0.51 & $\begin{array}{l}\text { Bactericidal, fungicidal and immu- } \\
\text { nomodulatory activity }\end{array}$ \\
\hline F1NZ37 & Cathepsin L1 & CTSL1 & $0.22^{*}$ & $0.48^{*}$ & $\begin{array}{l}\text { Controlling element of neutrophil } \\
\text { elastase activity }\end{array}$ \\
\hline P30374 & Ribonuclease homolog & RSFR & $0.23^{*}$ & 0.51 & Lysosomal cysteine protease \\
\hline P27042 & Lysozyme G & LYG2 & $0.24^{*}$ & 0.60 & Antimicrobial peptide \\
\hline F2Z4L6 & Serum albumin & ALB & $0.24^{*}$ & 0.67 & Plasma carrier \\
\hline P02789 & Ovotransferrin & OTFB & $0.26^{*}$ & 0.55 & Iron binding, immune response \\
\hline F1NGT3 & Matrix metallopeptidase 9 & MMP9 & $0.26^{*}$ & 0.77 & Degradation of the extracellular matrix \\
\hline F1NVM1 & G-protein coupled receptor 97 & GPR97 & $0.27^{*}$ & 0.66 & Regulates migration \\
\hline Q2IAL7 & Cathelicidin-2 & CATHL2 & $0.31^{*}$ & 0.78 & Antimicrobial peptide \\
\hline Q2UZR2 & Phosphoglucomutase 1 & PGM1 & $0.35^{*}$ & $0.43^{*}$ & Glucose metabolic process \\
\hline E1BZS2 & $\begin{array}{l}\text { Nucleosome assembly protein } \\
\text { 1-like }\end{array}$ & NAP1L1 & $0.36^{*}$ & $0.22^{*}$ & Chaperone for the linker histone \\
\hline P08940 & Myeloid protein 1 & LECT2 & $0.37^{*}$ & 0.62 & Chemotactic factor \\
\hline R4GH86 & Glutathione peroxidase & GPX & $0.41^{*}$ & 0.57 & $\begin{array}{l}\text { Protects organism from oxidative dam- } \\
\text { age }\end{array}$ \\
\hline F1NYH8 & Ena/VASP-like protein & EVL & $0.42^{*}$ & 0.70 & $\begin{array}{l}\text { Regulators of the actin cytoskeleton and } \\
\text { cell migration }\end{array}$ \\
\hline
\end{tabular}

* Significantly different from the expression in heterophils from the non-infected chickens.

increased the expression of lysosomal and phagosomal proteins what could be associated not only with $S$. Enteritidis inactivation but also with macrophage ability of antigen presentation.

Heterophils specifically expressed granular proteins MPO, LYZ, LYG2, RSFR, LECT2, CATHL1, CATHL2, CTSL1, CTSG, OTFB, SERPINB1 and MMP9, and endoplasmic reticulum proteins SSR1, PDIA4, PDIA6, PPIB, BiP, HSP90B1 and CANX. The latter group of proteins is activated when lumenal conditions in endoplasmic reticulum are altered or chaperone capacity is overwhelmed by unfolded or misfolded proteins [30]. Induction of an unfolded protein response leads to neutrophil degranulation in mice [31] and based on our results, a similar response can be predicted also in chicken heterophils.

Granular proteins decreased in heterophils in response to infection. Since transcription of genes encoding these proteins did not change and the number of ribosomal proteins increased, these genes must have remained continuously transcribed and translated even after initial degranulation [24, 32-35]. However, not all proteins that decreased in heterophils following $S$. Enteritidis infection were assigned to pathogen inactivation. Matrix metalloproteinase MMP9 is used for degradation of the extracellular matrix to enable leukocyte infiltration to the site of inflammation [36], and ALB and FN1, are found at the surface of granulocytes and inhibit their migration [37, 38]. The decrease of ALB and FN1 together with the degradation of extracellular matrix by MMP9 leads to heterophil translocation from the blood circulation to the site of inflammation.

Comparing expression at the protein and RNA levels provided several unexpected results. Changes in expression at the RNA level in response to infection were more pronounced in heterophils than in macrophages. We can exclude any technical issues in macrophage gene expression analysis since there were at least 3 genes inducible at the RNA level also in macrophages (AVD, MRP126 and F13A). Unlike macrophages, there were also greater differences in the expression profiles of heterophils 
Table 5 Proteins of increased or decreased abundance in macrophages in response to S. Enteritidis infection

\begin{tabular}{|c|c|c|c|c|c|}
\hline Acc. no. & Protein name & Gene ID & $\begin{array}{l}\text { Fold ratio } \\
\text { inf:noninf }\end{array}$ & $\begin{array}{l}\text { Fold ratio } \\
\text { vac:noninf }\end{array}$ & Function \\
\hline P28318 & MRP126, calprotectin & MRP126 & $15.67^{*}$ & $5.01^{*}$ & Calcium and zinc binding \\
\hline Q6QLQ5 & Cathelicidin-1 & CATHL1 & $7.32^{*}$ & $2.95^{*}$ & Antimicrobial peptide \\
\hline P30374 & Ribonuclease homolog & RSFR & $5.84^{*}$ & 1.66 & Lysosomal cysteine protease \\
\hline F1NIX4 & Trans-2-enoyl-CoA reductase & MECR & $5.47^{*}$ & $3.99^{*}$ & Fatty acid elongation \\
\hline P46156 & Gallinacin 1 & GAL1 & $4.15^{*}$ & 1.12 & Antimicrobial protein \\
\hline F1N8Q1 & Superoxide dismutase & SOD1 & $4.01^{*}$ & 2.58 & Oxygen scavenger \\
\hline P08940 & Myeloid protein 1 & LECT2 & $3.87^{*}$ & 1.35 & Chemotactic factor for Het \\
\hline F1P4F3 & Lymphocyte antigen 86, MD-1 & LY86 & $3.53^{*}$ & 3.03 & Inhibits LPS response of immune cells \\
\hline F1NS91 & $60 S$ ribosomal protein $L 9$ & RPL9 & $3.51^{*}$ & 3.82 & Structural part of ribosome \\
\hline E1BTT4 & $\begin{array}{l}\text { Trifunctional enzyme subunit beta, } \\
\text { mitochondrial }\end{array}$ & $\mathrm{HADHB}$ & $3.38^{*}$ & $3.54^{*}$ & $\beta$-Oxidation of fatty acids \\
\hline P43233 & Cathepsin B & CTSB & $2.88^{*}$ & $2.57^{*}$ & Lysosomal cysteine protease \\
\hline B4X9P4 & Microsomal glutathione S-transferase 1 & MGST1 & $2.87^{*}$ & 1.46 & $\begin{array}{l}\text { Membrane protection from oxidative } \\
\text { stress }\end{array}$ \\
\hline Q5ZMP2 & Syntaxin 7 & STX7 & $2.72^{*}$ & $2.94^{*}$ & Late endosome-lysosome fusion \\
\hline E1COF3 & Ras-related protein Rab-7a & RAB7A & $2.69^{*}$ & $2.38^{*}$ & $\begin{array}{l}\text { Involved in endocytosis, phagosome- } \\
\text { lysosome fusion }\end{array}$ \\
\hline F1N9J7 & Tubulin alpha-3 chain & Tuba3a & $2.63^{*}$ & 1.96 & Major constituent of microtubules \\
\hline P08267 & Ferritin heavy chain & FTH & $2.62^{*}$ & $2.33^{*}$ & $\begin{array}{l}\text { Storage of iron in a soluble, nontoxic } \\
\text { state }\end{array}$ \\
\hline P02263 & Histone H2A-IV & $\mathrm{H} 2 \mathrm{~A} 4$ & $2.61^{*}$ & $3.64^{*}$ & Formation of nucleosome \\
\hline F1NWG2 & Cathepsin C & CTSC & $2.48^{*}$ & $2.46^{*}$ & Activates serine proteases \\
\hline Q2IAL7 & Cathelicidin-2 & CATHL2 & $2.45^{*}$ & 1.01 & Antimicrobial peptide \\
\hline Q6EE32 & Calreticulin & CALR & $2.33^{*}$ & $2.21^{*}$ & Molecular chaperon \\
\hline Q919D1 & $\begin{array}{l}\text { Voltage-dependent anion-selective chan- } \\
\text { nel protein } 2\end{array}$ & VDAC2 & $2.27^{*}$ & $2.07^{*}$ & Inhibits mitochondrial way of apoptosis \\
\hline P02607 & Myosin light polypeptide 6 & MYL6 & $2.7^{*}$ & 1.66 & Found in phagosome \\
\hline F1NB92 & Endoplasmic reticulum aminopeptidase 1 & ERAP1 & $2.21^{*}$ & 2.04 & $\begin{array}{l}\text { Antigen processing and presentation of } \\
\text { endogenous peptide via MHC class I }\end{array}$ \\
\hline E1BTT8 & Lactate dehydrogenase A & LDHA & $2.07^{*}$ & 1.71 & Glycolysis \\
\hline R4GM10 & Fructose-bisphosphate aldolase C & ALDOC & $2.07^{*}$ & 2.33 & Glycolysis \\
\hline P24367 & Peptidyl-prolyl cis-trans isomerase B & PPIB & $2.00^{*}$ & 0.97 & $\begin{array}{l}\text { Regulation of protein folding and } \\
\text { maturation }\end{array}$ \\
\hline Q5ZKQ9 & RNA binding motif protein, $\mathrm{X}$-linked & RBMX & $0.49^{*}$ & 0.59 & $\begin{array}{l}\text { Regulation of pre- and post-transcrip- } \\
\text { tional processes }\end{array}$ \\
\hline R4GGZ2 & $\begin{array}{l}\text { NADH dehydrogenase [ubiquinone] } 1 \\
\text { alpha subcomplex subunit } 4\end{array}$ & NDUFA4 & $0.38^{*}$ & 0.65 & Oxidative phosphorylation \\
\hline E1BYF8 & Formin-binding protein 1 & FNBP1 & $0.33^{*}$ & $0.47^{*}$ & $\begin{array}{l}\text { Role in late stage of clathrin-mediated } \\
\text { endocytosis }\end{array}$ \\
\hline R4GJP1 & $\begin{array}{l}\text { Family with sequence similarity } 107 \text {, } \\
\text { member B }\end{array}$ & FAM107 & $0.32^{*}$ & $0.30^{*}$ & Candidate tumor suppressor gene \\
\hline P31395 & Stathmin 1 & STMN1 & $0.27^{*}$ & 0.51 & Promotes disassembly of microtubules \\
\hline $\mathrm{E} 1 \mathrm{BQ} \mid 4$ & Glyoxalase domain-containing protein 4 & GLOD4 & $0.21^{*}$ & $0.18^{*}$ & Unknown \\
\hline Q5ZM25 & Obg-like ATPase 1 & OLA1 & $0.12^{*}$ & 0.11 & $\begin{array}{l}\text { Negative role in cell adhesion and } \\
\text { spreading }\end{array}$ \\
\hline
\end{tabular}

* Significantly different from the expression in macrophages from the non-infected chickens.

obtained from vaccinated chickens in comparison to those obtained from naive but infected animals and an increase in CATHL2 and LECT2 in the heterophils from the vaccinated chickens following $S$. Enteritidis challenge appeared as a specific positive marker of vaccination. Despite this, expression in heterophils and macrophages in naive but infected chickens tended to approach a similar expression profile (Figure 2). 

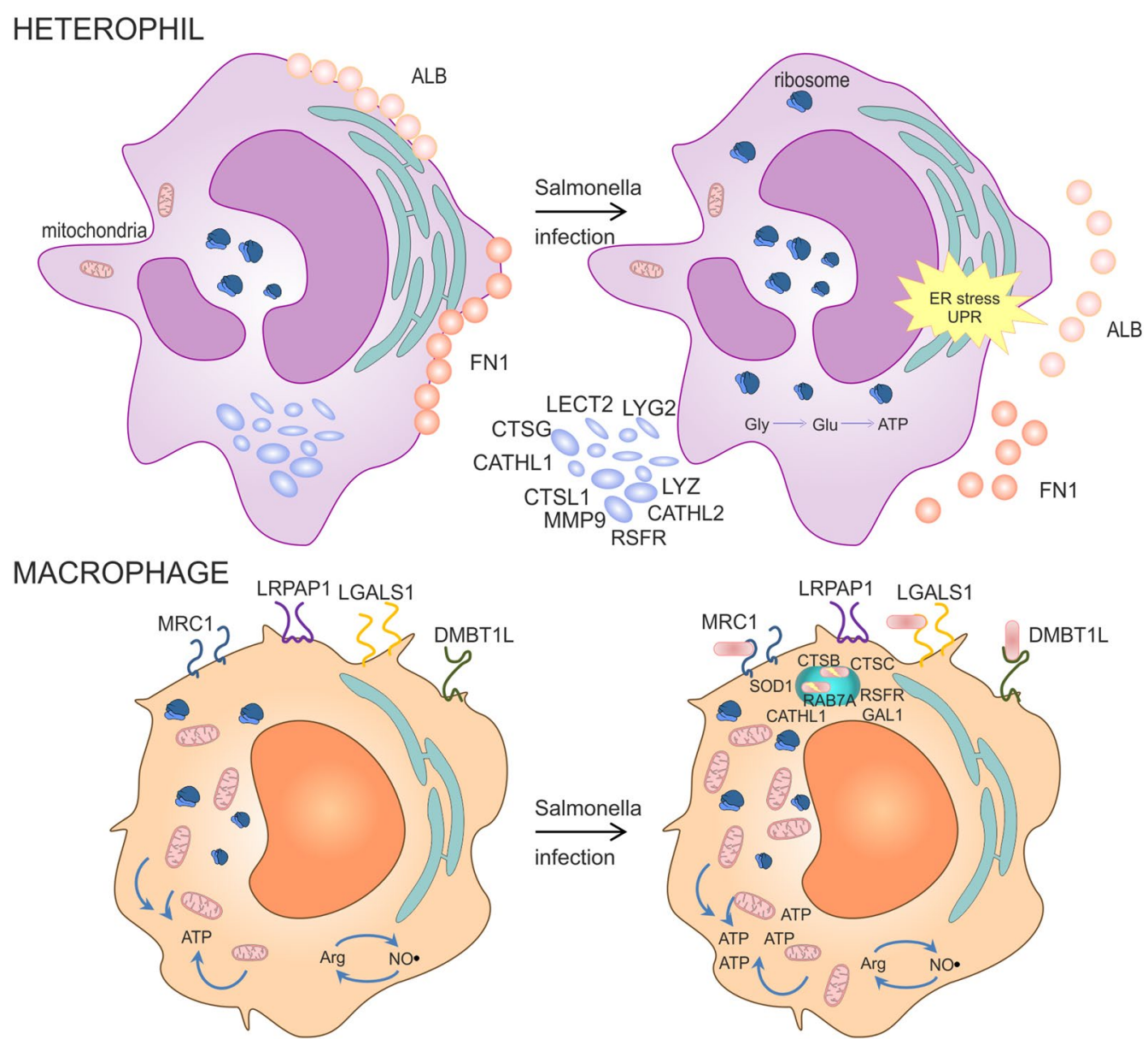

Figure 1 The most characteristic proteins and their functions in chicken heterophils and macrophages. Heterophils express MMP9, MRP126, LECT2, CATHL1, CATHL2, CATHL3, LYG2, LYZ and RSFR proteins. Following S. Enteritidis infection, heterophils decreased fibrinogen FN1 and albumin ALB, and increased ribosomal proteins. In addition, endoplasmic reticulum proteins are activated which results in the release of granular proteins. Heterophils expressed glycogen (Gly) metabolism pathway which allows for rapid glucose (Glu) availability and anaerobic ATP generation via glycolysis while macrophages increased mitochondrial activity. Macrophages expressed receptor proteins MRC1, LGALS1, LRPAP1 and DMBT1L, mitochondria-localized proteins and arginine metabolism proteins. Following infection with $S$. Enteritidis, macrophages increased the expression of lysosomal and phagosomal proteins (CTSB, CTSC, RAB7A, CATHL1, RSFR, GAL1, SOD1).

In this study we characterized protein expression in chicken heterophils and macrophages in response to intravenous infection with $S$. Enteritidis. Heterophils decreased ALB and FN1, and released MMP9 to enable their translocation to the site of infection. Secondly the endoplasmic reticulum proteins increased in heterophils which resulted in the release of granular proteins. On the other hand, macrophages were less responsive to acute infection and an increase in proteins like CATHL1, CATHL2, RSFR, LECT2 and GAL1 in the absence of any 


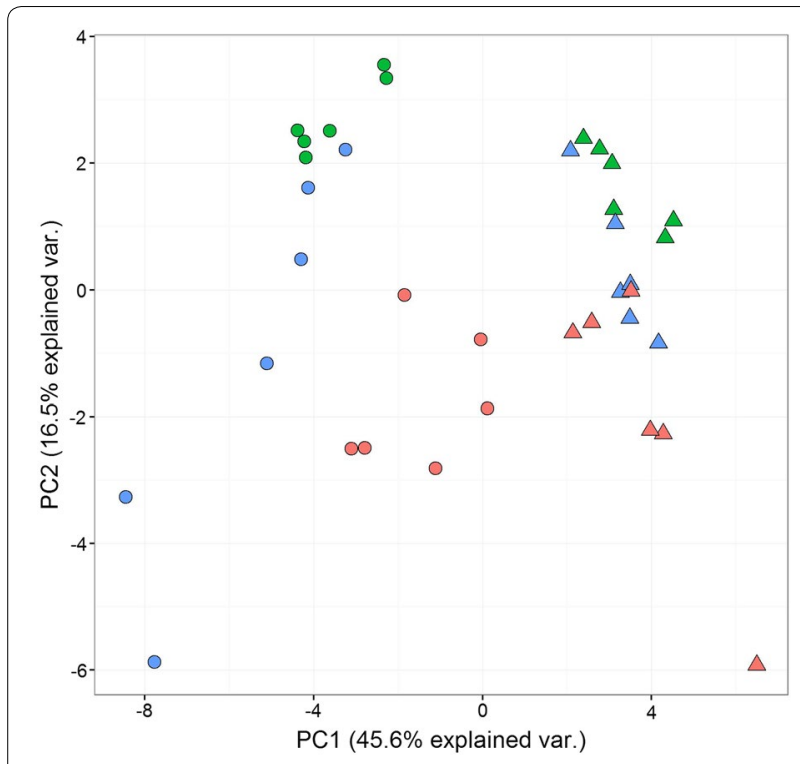

Figure 2 PCA cluster analysis of chicken heterophils and macrophages using expression data from qPCR. Each spot represents heterophils (circles) or macrophages (triangles) isolated from non-infected (green color), infected (red color), and vaccinated and infected chickens (blue color), 6 chickens per group. Heterophils from vaccinated chickens responded to infection more than macrophages from the same chicken. Transcription of heterophils and macrophages from naive but infected chickens approached the same profile.

change in their expression at RNA level could even be explained by capturing these proteins from the external environment into which these could have been released by heterophils.

\section{Additional files}

\section{Additional file 1. List of primers used in quantitative RT PCR in the} study.

Additional file 2. Identification of heterophil and macrophage specific proteins using label-free LC MS/MS and PSM quantification.

Additional file 3 . Heterophil proteins responding to in vivo infection with $S$. Enteritidis.

Additional file 4. All heterophil proteins quantified in this study.

Additional file 5. Macrophage proteins responding to in vivo infection with S. Enteritidis.

Additional file 6. All macrophage proteins quantified in this study.

Additional file 7. Expression of selected genes at RNA level determined by quantitative RT PCR.

\section{Competing interests}

The authors declare that they have no competing interests.

\section{Authors' contributions}

ZS and OP purified proteins and performed protein mass spectrometry. HS and RF sorted splenic leukocytes by flow cytometry. KV and MF were responsible for RNA purification and GPCR. IR and LV designed the study, analysed data and wrote the manuscript. All authors read and approved the final manuscript.

\section{Acknowledgements}

Authors would like to thank Peter Eggenhuizen for language corrections and acknowledge the excellent technical assistance of Andrea Durisova.

\section{Author details}

${ }^{1}$ Veterinary Research Institute, Hudcova 70, 62100 Brno, Czech Republic. ${ }^{2}$ Department of Cytokinetics, Institute of Biophysics of the CAS, Kralovopolska 135, 61265 Brno, Czech Republic. ${ }^{3}$ Center of Biomolecular and Cellular Engineering, International, Clinical Research Center, St. Anne's University Hospital Brno, Pekarska 53, 65691 Brno, Czech Republic.

\section{Funding}

This work has been supported by project from P502-13-31474P of the Czech Science Foundation, AdmireVet project CZ.1.005/2.1.00/01.0006ED0006/01/01 from the Czech Ministry of Education and RO0516 project of the Czech Ministry of Agriculture. RF was supported by the project LQ1605 from the National Program of Sustainability II (MEYS CR). The funders had no role in the study design, data collection and analysis, decision to publish, or preparation of the manuscript.

\section{Publisher's Note}

Springer Nature remains neutral with regard to jurisdictional claims in published maps and institutional affiliations.

Received: 15 January 2017 Accepted: 23 May 2017

Published online: 17 June 2017

\section{References}

1. Silva MT (2010) When two is better than one: macrophages and neutrophils work in concert in innate immunity as complementary and cooperative partners of a myeloid phagocyte system. J Leukoc Biol 87:93-106

2. Genovese KJ, He H, Swaggerty CL, Kogut MH (2013) The avian heterophil. Dev Comp Immunol 41:334-340

3. Kogut MH, McGruder ED, Hargis BM, Corrier DE, DeLoach JR (1995) In vivo activation of heterophil function in chickens following injection with Salmonella Enteritidis-immune lymphokines. J Leukoc Biol 57:56-62

4. Kogut MH, Tellez G, Hargis BM, Corrier DE, DeLoach JR (1993) The effect of 5-fluorouracil treatment of chicks: a cell depletion model for the study of avian polymorphonuclear leukocytes and natural host defenses. Poult Sci 72:1873-1880

5. Barrow PA (2007) Salmonella infections: immune and non-immune protection with vaccines. Avian Pathol 36:1-13

6. Matulova M, Rajova J, Vlasatikova L, Volf J, Stepanova H, Havlickova H, Sisak F, Rychlik I (2012) Characterization of chicken spleen transcriptome after infection with Salmonella enterica serovar Enteritidis. PLoS One 7:e48101

7. Matulova M, Stepanova H, Sisak F, Havlickova H, Faldynova M, Kyrova K, Volf J, Rychlik I (2012) Cytokine signaling in splenic leukocytes from vaccinated and non-vaccinated chickens after intravenous infection with Salmonella Enteritidis. PLoS One 7:e32346

8. Qureshi MA (2003) Avian macrophage and immune response: an overview. Poult Sci 82:691-698

9. Swaggerty CL, Pevzner IY, Kaiser P, Kogut MH (2008) Profiling pro-inflammatory cytokine and chemokine mRNA expression levels as a novel method for selection of increased innate immune responsiveness. Vet Immunol Immunopathol 126:35-42

10. Singh R, Jain P, Pandey NK, Saxena VK, Saxena M, Singh KB, Ahmed KA, Singh RP (2012) Cytokines expression and nitric oxide production under induced infection to Salmonella Typhimurium in chicken lines divergently selected for cutaneous hypersensitivity. Asian-Australas J Anim Sci 25:1038-1044

11. Rychlik I, Karasova D, Sebkova A, Volf J, Sisak F, Havlickova H, Kummer V, Imre A, Szmolka A, Nagy B (2009) Virulence potential of five major 
pathogenicity islands (SPI-1 to SPI-5) of Salmonella enterica serovar Enteritidis for chickens. BMC Microbiol 9:268

12. Bustin SA, Benes V, Garson JA, Hellemans J, Huggett J, Kubista M, Mueller R, Nolan T, Pfaffl MW, Shipley GL, Vandesompele J, Wittwer CT (2009) The MIQE guidelines: minimum information for publication of quantitative real-time PCR experiments. Clin Chem 55:611-622

13. De Boever S, Vangestel C, De Backer P, Croubels S, Sys SU (2008) Identification and validation of housekeeping genes as internal control for gene expression in an intravenous LPS inflammation model in chickens. Vet Immunol Immunopathol 122:312-317

14. Li YP, Bang DD, Handberg KJ, Jorgensen PH, Zhang MF (2005) Evaluation of the suitability of six host genes as internal control in real-time RT-PCR assays in chicken embryo cell cultures infected with infectious bursal disease virus. Vet Microbiol 110:155-165

15. Wiśniewski JR, Zougman A, Nagaraj N, Mann M (2009) Universal sample preparation method for proteome analysis. Nat Methods 6:359-362

16. Boersema PJ, Raijmakers R, Lemeer S, Mohammed S, Heck AJ (2009) Multiplex peptide stable isotope dimethyl labeling for quantitative proteomics. Nat Protoc 4:484-494

17. Lundgren DH, Hwang SI, Wu L, Han DK (2010) Role of spectral counting in quantitative proteomics. Expert Rev Proteomics 7:39-53

18. Old WM, Meyer-Arendt K, Aveline-Wolf L, Pierce KG, Mendoza A, Sevinsky $J R$, Resing KA, Ahn NG (2005) Comparison of label-free methods for quantifying human proteins by shotgun proteomics. Mol Cell Proteomics 4:1487-1502

19. Wong JW, Sullivan MJ, Cagney G (2008) Computational methods for the comparative quantification of proteins in label-free LCn-MS experiments. Brief Bioinform 9:156-165

20. Adeva-Andany MM, González-Lucán M, Donapetry-García C, FernándezFernández C, Ameneiros-Rodríguez E (2016) Glycogen metabolism in humans. BBA Clin 5:85-100

21. Staines K, Hunt LG, Young JR, Butter C (2014) Evolution of an expanded mannose receptor gene family. PLoS One 9:e110330

22. Li YZ, Cheng CS, Chen CJ, Li ZL, Lin YT, Chen SE, Huang SY (2014) Functional annotation of proteomic data from chicken heterophils and macrophages induced by carbon nanotube exposure. Int J Mol Sci 15:8372-8392

23. Ye H, Xu FZ, Yu WY (2009) The intracellular localization and oligomerization of chicken invariant chain with major histocompatibility complex class II subunits. Poult Sci 88:1594-1600

24. van Dijk A, Molhoek EM, Veldhuizen EJ, Bokhoven JL, Wagendorp E, Bikker F, Haagsman HP (2009) Identification of chicken cathelicidin-2 core elements involved in antibacterial and immunomodulatory activities. Mol Immunol 46:2465-2473
25. van Dijk A, Tersteeg-Zijderveld MH, Tjeerdsma-van Bokhoven JL, Jansman AJ, Veldhuizen EJ, Haagsman HP (2009) Chicken heterophils are recruited to the site of Salmonella infection and release antibacterial mature Cathelicidin-2 upon stimulation with LPS. Mol Immunol 46:1517-1526

26. Novak R, Dabelic S, Dumic J (2012) Galectin-1 and galectin-3 expression profiles in classically and alternatively activated human macrophages. Biochim Biophys Acta 1820:1383-1390

27. May P, Bock HH, Nofer JR (2013) Low density receptor-related protein 1 (LRP1) promotes anti-inflammatory phenotype in murine macrophages. Cell Tissue Res 354:887-889

28. Kramer PA, Ravi S, Chacko B, Johnson MS, Darley-Usmar VM (2014) A review of the mitochondrial and glycolytic metabolism in human platelets and leukocytes: implications for their use as bioenergetic biomarkers. Redox Biol 2:206-210

29. Hussain I, Qureshi MA (1997) Nitric oxide synthase activity and mRNA expression in chicken macrophages. Poult Sci 76:1524-1530

30. Lai E, Teodoro T, Volchuk A (2007) Endoplasmic reticulum stress: signaling the unfolded protein response. Physiology (Bethesda) 22:193-201

31. Hu R, Chen ZF, Yan J, Li QF, Huang Y, Xu H, Zhang XP, Jiang H (2015) Endoplasmic reticulum stress of neutrophils is required for ischemia/ reperfusion-induced acute lung injury. J Immunol 195:4802-4809

32. Rosenberg HF (2008) RNase A ribonucleases and host defense: an evolving story. J Leukoc Biol 83:1079-1087

33. Veldhuizen EJ, Brouwer EC, Schneider VA, Fluit AC (2013) Chicken cathelicidins display antimicrobial activity against multiresistant bacteria without inducing strong resistance. PLoS One 8:e61964

34. Johnson DA, Barrett AJ, Mason RW (1986) Cathepsin L inactivates alpha 1-proteinase inhibitor by cleavage in the reactive site region. J Biol Chem 261:14748-14751

35. Baumann M, Pham CT, Benarafa C (2013) SerpinB1 is critical for neutrophil survival through cell-autonomous inhibition of cathepsin G. Blood 121:3900-3907

36. Bradley LM, Douglass MF, Chatterjee D, Akira S, Baaten BJ (2012) Matrix metalloprotease 9 mediates neutrophil migration into the airways in response to influenza virus-induced toll-like receptor signaling. PLoS Pathog 8:e1002641

37. Nathan C, Xie QW, Halbwachs-Mecarelli L, Jin WW (1993) Albumin inhibits neutrophil spreading and hydrogen peroxide release by blocking the shedding of CD43 (sialophorin, leukosialin). J Cell Biol 122:243-256

38. Everitt EA, Malik AB, Hendey B (1996) Fibronectin enhances the migration rate of human neutrophils in vitro. J Leukoc Biol 60:199-206

\section{Submit your next manuscript to BioMed Central and we will help you at every step:}

- We accept pre-submission inquiries

- Our selector tool helps you to find the most relevant journal

- We provide round the clock customer support

- Convenient online submission

- Thorough peer review

- Inclusion in PubMed and all major indexing services

- Maximum visibility for your research

Submit your manuscript at www.biomedcentral.com/submit
() Biomed Central 